\title{
Association of dead space ventilation and prolonged ventilation after repair of tetralogy of Fallot with pulmonary atresia
}

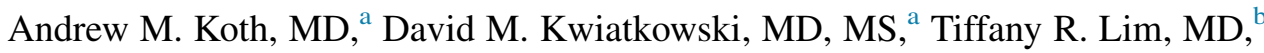 \\ Holly Bauser-Heaton, MD, PhD, ${ }^{\mathrm{a}}$ Ritu Asija, MD, ${ }^{\mathrm{a}}$ Doff B. McElhinney, MD, ${ }^{\mathrm{c}}$ Frank L. Hanley, $\mathrm{MD},{ }^{\mathrm{c}}$ and \\ Catherine D. Krawczeski, MD
}

\section{ABSTRACT}

Background: We set out to determine whether patients with tetralogy of Fallot with pulmonary atresia and major aortopulmonary collateral arteries (TOF/PA/ MAPCA) are at risk for elevated dead space ventilation fraction (VD/VT), and whether this is associated with prolonged mechanical ventilation. We hypothesized that elevated VD/VT $(>20 \%)$ in the first 24 hours after unifocalization surgery is associated with increased risk for prolonged mechanical ventilation ( $>7$ days).

Methods: All patients with TOF/PA/MAPCA undergoing unifocalization surgery between January 2003 and December 2015 were included in this study. Average VD/VT was calculated over the first 24 hours after surgery. Demographic and surgical data were collected. Outcome data included duration of mechanical ventilation. Patients were separated into 2 groups: elevated VD/VT and normal DVSF. Groups were compared using the Student $t$ test, Wilcoxon rank-sum test, and $\chi^{2}$ test. Univariable and multivariable regression analyses were performed with VD/VT as a continuous variable to test for association.

Results: Of the 265 included patients, 127 (48\%) had an elevated VD/VT. The 2 groups did not differ significantly in any demographic characteristic. Patients with an elevated VD/VT had longer cardiopulmonary bypass times $(P=.03)$, were more likely to have delayed sternal closure, and more likely to have prolonged respiratory failure (odds ratio, $2.2 ; 95 \%$ confidence interval, $1.2-4.0 ; P=.007$ ). The percent VD/VT was associated with duration of mechanical ventilation in univariable $(P<.001)$ and multivariable $(P<.001)$ regression analyses when controlled for age, weight and bypass time.

Conclusions: Elevated postoperative VD/VT is associated with prolonged mechanical ventilation in patients with TOF/PA/MAPCA following unifocalization. Elevated postoperative VD/VT may be an early indicator of patients who will require prolonged duration of mechanical ventilation, allowing optimization of medical management to promote better outcomes. (J Thorac Cardiovasc Surg 2018;156:1181-7)

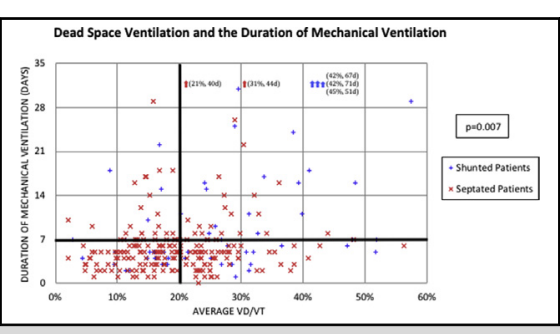

Duration of mechanical ventilation versus 24-hour average VD/NT.

\section{Central Message}

Increased dead-space ventilation fraction is associated with prolonged ventilation in patients with TOF/PA/MAPCA after unifocalization and, if identified, may allow caregivers to optimize care and improve outcomes.

\section{Perspective}

Children with TOF/PA/MAPCA are at risk for increased dead-space ventilation fraction (VD/VT) following unifocalization, which is associated with prolonged mechanical ventilation. Elevated VD/VT has been associated with poor outcomes in patients with congenital heart disease but has not been described in these patients. Our findings can help predict the postoperative course and allow for treatment optimization.

See Editorial Commentary page 1188

See Editorial page 1179.

\footnotetext{
From the ${ }^{a}$ Division of Pediatric Cardiology, Department of Pediatrics, and Departments of ${ }^{\mathrm{b}}$ Pediatrics and ${ }^{\mathrm{c}}$ Cardiothoracic Surgery, Stanford University, Palo Alto, Calif.

Received for publication March 24, 2017; revisions received April 17, 2018; accepted for publication April 21, 2018; available ahead of print June 5, 2018.

Address for reprints: Andrew M. Koth, MD, Division of Pediatric Cardiology, 750 Welch Rd, Suite 325, Palo Alto, CA 94304 (E-mail: akoth@stanford.edu). $0022-5223 / \$ 36.00$

Copyright (c) 2018 by The American Association for Thoracic Surgery https://doi.org/10.1016/j.jtcvs.2018.04.088
}

The care of patients with tetralogy of Fallot with pulmonary atresia and major aortopulmonary collaterals (TOF/PA/MAPCA) presents both surgical and medical

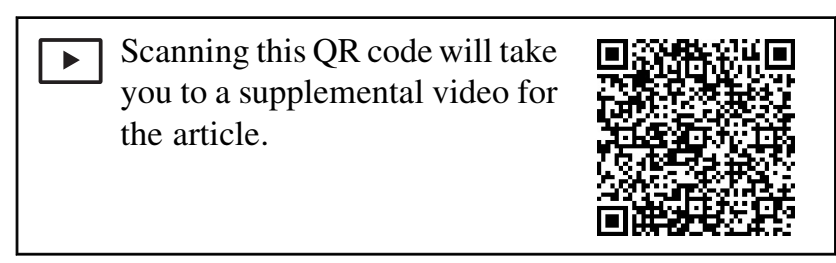




$\begin{array}{ll}\text { Abbreviations and } & \text { Acronyms } \\ \mathrm{CI} & =\text { confidence interval } \\ \mathrm{CPB} & =\text { cardiopulmonary bypass } \\ \mathrm{ICU} & =\text { intensive care unit } \\ \mathrm{OR} & =\text { odds ratio } \\ \mathrm{PaCO}_{2} & \text { arterial partial pressure of } \\ & \text { carbon dioxide } \\ \mathrm{ROC} & \text { receiver operating } \\ & \text { characteristic } \\ \mathrm{RV} & =\text { right ventricle } \\ \mathrm{TOF} / \mathrm{PA} / \mathrm{MAPCA}= & \text { tetralogy of Fallot with } \\ & \text { pulmonary atresia and major } \\ & \text { aortopulmonary collateral } \\ \mathrm{VD} / \mathrm{VT} & \text { arteries } \\ \mathrm{VSD} & =\text { dead space ventilation fraction } \\ & =\text { ventricular septal defect }\end{array}$

challenges. The surgical procedures (unifocalization/pulmonary artery reconstruction) performed in these patients are often complex, leading to a complicated postoperative course in the cardiovascular intensive care unit (ICU). After surgery, patients may require prolonged mechanical ventilation, impacting the ICU and hospital lengths of stay.

Both delayed sternal closure and postoperative respiratory infections have been associated with prolonged mechanical ventilation in this population. ${ }^{1}$ Prolonged mechanical ventilation has been associated with poor outcomes in many populations. ${ }^{2-11}$ Numerous postoperative factors have been associated with poor outcomes after congenital cardiac surgery, including renal injury, ${ }^{12}$ level of vasopressor support, ${ }^{13}$ and blood transfusions, ${ }^{14}$ but few studies ${ }^{15}$ have looked at respiratory parameters, such as dead space ventilation fraction (VD/VT). This is the first study to describe the association of VD/VT with postoperative respiratory outcomes in children undergoing unifocalization surgery.

An elevated VD/VT has been described in normal children $^{16-18}$ and children undergoing cardiac surgery ${ }^{19}$ and has been established as a risk factor for prolonged respiratory failure and increased hospital length of stay after stage 1 single-ventricle palliative surgery. ${ }^{20}$ The same association was observed in a prospective study of VD/VT in patients with various forms of congenital heart disease undergoing cardiac surgery, with the exception of patients with residual shunt physiology. ${ }^{21}$

The management of patients with TOF/PA/MAPCA includes establishing pulmonary blood flow to all lung segments to achieve the lowest possible right ventricular pressure to optimize the risk of ventricular septal defect (VSD) closure. If it is deemed that the pulmonary vascular bed requires growth and/or the pulmonary arterial pressure would be too high, a shunt is placed into the unifocalized pulmonary vascular bed. ${ }^{22}$ Thus, patients undergo either unifocalization with complete intracardiac repair (VSD closure) or unifocalization to a central shunt. No patients underwent unifocalization with placement of a right ventricle (RV) to pulmonary artery conduit without VSD closure. Although this is the end goal, at times there still may be differential perfusion, which could lead to elevated VD/VT. During unifocalization surgery, there is extensive intraparenchymal dissection with resultant airway edema, bronchospasm, and air-trapping, along with arterial vasoconstriction and areas of impaired perfusion. These factors contribute to elevated VD/VT, but the degree and importance of elevated VD/VT in patients with TOF/PA/MAPCA undergoing unifocalization is unknown.

Given the mechanism of injury and high potential for elevated VD/VT in the postoperative period after unifocalization, we hypothesized that elevated VD/VT (defined as $>20 \%$ ) in the first 24 postoperative hours would be associated with prolonged respiratory failure ( $>7$ days) in patients with TOF/PA/MAPCA. If this physiological perturbation is detected and shown to be a risk factor, early interventions, such as bronchodilator or mucolytic therapy, antiinflammatory agents, inhaled nitric oxide, and modification of ventilation strategies, could be used to improve ventilation-perfusion matching and potentially decrease the duration of mechanical ventilation and ICU length of stay. Our primary aim was to establish the incidence of elevated VD/VT in this patient population and to determine its association with prolonged postoperative respiratory failure.

\section{METHODS \\ Patients}

All patients age $<18$ years with TOF/PA/MAPCA old undergoing unifocalization surgery between January 2003 and December 2015 at Lucile Packard Children's Hospital Stanford were included in the inception cohort for this retrospective cohort study. The cohort was established by interrogating a PA/MAPCA REDCap database that is maintained by the Clinical and Translational Research Program of the Heart Center at Lucile Packard Children's Hospital Stanford. Patients were excluded if they underwent only an aortopulmonary window (without dissection of collateral arteries), never underwent unifocalization at Stanford, had preoperative pulmonary hypertension, had undergone tracheostomy preoperatively, were placed on extracorporeal membrane oxygenation in the first 24 postoperative hours, remained intubated for an additional procedure, or had fewer than 3 recorded paired end-tidal $\mathrm{CO}_{2}$ and arterial partial pressure of $\mathrm{CO}_{2}$ $\left(\mathrm{PaCO}_{2}\right)$ measurements after returning to the cardiovascular ICU after unifocalization. This study was approved by Stanford University's Institutional Review Board.

\section{Data Collection}

Demographic data, including age, sex, weight, and length, were recorded. Clinical data collected including cardiopulmonary bypass (CPB) time, aortic cross-clamp time, time to initial extubation after surgery, status of chest (open or closed in the operating room), length of time that the chest remained open, ICU and hospital lengths of stay, number of vessels 
unifocalized, RV:left ventricle pressure ratio in the operating room (for those who underwent VSD closure), and paired end-tidal $\mathrm{CO}_{2}$ and $\mathrm{PaCO}_{2}$ from an arterial blood gas analysis. To be included as data points in the study, the end-tidal $\mathrm{CO}_{2}$ and $\mathrm{PaCO}_{2}$ needed to be obtained within 1 hour of each other. The end-tidal $\mathrm{CO}_{2}$ and $\mathrm{PaCO}_{2}$ values were then used to calculate VD/VT using the Enghoff modification of the Bohr equation:

$$
\frac{V D}{V T}=\frac{\mathrm{PaCO}_{2}-\mathrm{PeCO}_{2}}{\mathrm{PaCO}_{2}}
$$

where $\mathrm{PeCO}_{2}$ is the partial pressure of carbon dioxide in the expired (exhaled) air.

Elevated VD/VT was defined ad hoc as $>20 \%$. To date, few studies have examined VD/VT in normal subjects, although some studies have suggested that a normal VD/VT is closer to $35 \% .{ }^{19}$ In truth, the normal value may be widely variable. We chose $20 \%$ as a cutoff before data collection for a study of this specific cohort, and this was correlated with the approximate median of the sample.

\section{Data Analysis}

Average VD/VT was calculated over the first 24 postoperative hours. The cohort was separated into 2 groups: those with elevated VD/VT $(>20 \%)$ and those with normal VD/VT. The cutoff value for elevated VD/VT was chosen ad hoc as a clinically relevant level that was near the median for the cohort. Prolonged mechanical ventilation was defined as a duration of mechanical ventilator support for $\geq 7$ days. This duration was chosen ad hoc as a clinically relevant period that also matched the upper quartile of mechanical ventilation use. We tested all collected data for normalcy. Groups were compared using the Student $t$, Wilcoxon rank-sum, and $\chi^{2}$ tests, as appropriate. Variables were expressed as either mean with standard deviation or median with interquartile range. Odds ratios (ORs) are presented with $95 \%$ confidence intervals (CIs).

Univariable and multivariable regression analysis was performed with VD/VT as a discreet and continuous variable to test for association with outcome. Natural logarithmic transformation was used when the outcome was nonlinear. Variables were selected for entry into the multivariable model based on Pearson correlation $(P<.10)$. We also performed subgroup analysis to separately study patients who underwent unifocalization of collateral vessels with placement of an aortopulmonary shunt and those who underwent complete intracardiac repair intracardiac repair with closure of the VSD and RV-to-pulmonary artery conduit placement. A scatterplot of VD/VT and duration of mechanical ventilation was created to identify whether any clinically significant predictors could be identified based on the degree of VD/VT. The scatterplot was also used to establish negative predictive values for prolonged mechanical ventilation. A receiver operator characteristic (ROC) curve was generated for prediction of prolonged mechanical ventilation. Cutpoint analysis was performed to find the level of VD/VT that would result in a sensitivity of at least $70 \%$ with a specificity of at least $50 \%$.

All statistical tests were performed with SPSS version 23.0 (IBM, Armonk, NY). A $P$ value $<.05$ was considered statistically significant.

\section{RESULTS}

A total of 265 patients met the criteria for study inclusion (Figure 1), including 128 patients with elevated VD/VT and 138 patients with normal VD/VT. The 2 groups were similar with respect to the variables listed in Table 1 . All patients included in the study had sufficient data to calculate average VD/VT in the first 24 hours after surgery.

Patients with elevated VD/VT had longer CPB times and were more likely to undergo delayed sternal closure, although the average time with the sternum left open was similar in the 2 groups ( 3.9 days for those with elevated $\mathrm{VD} / \mathrm{VT}$ and 3.6 days with normal VD/VT). They were also more likely than those with normal VD/VT to have prolonged mechanical ventilation $(\mathrm{OR}, 2.2 ; 95 \% \mathrm{CI}, 1.2-4$; $P=.007$ ) (Table 2). Using VD/VT as a continuous variable and length of mechanical ventilation as a dichotomous variable (prolonged vs not), we found that for each percentile increase in VD/VT there was a 5\% increase in the likelihood of having a prolonged duration of mechanical ventilation $(\beta=5.03 ; P=<.001)$. Figure 2 depicts the relationship of VD/VT and duration of mechanical ventilation, with bold lines at 7 days of mechanical ventilation and a VD/VT of $20 \%$.

This association was maintained in multivariable regression analysis. When controlling for open chest, weight, unifocalized collaterals, and CPB, an increased VD/VT was significantly associated with prolonged duration of mechanical ventilation $(P=.021)$. All of the variables in the multivariable model had complete data.

Our ROC curve (Figure 3) identified VD/VT as a good predictor for prolonged mechanical ventilation, with an area under the ROC curve of $0.712(P<.001)$. A VD/VT value of 0.187 had optimal predictive properties with a sensitivity of $72 \%$ and a specificity of $50 \%$. The negative predictive value of VD/VT of 0.187 was $85.7 \%$, and the positive predictive value was $30 \%$.

Most patients who were intubated for an extremely long duration ( $\geq 14$ days) had a VD/VT of $>20 \%$. Using this analysis, the negative predictive value for prolonged mechanical ventilation of $\geq 7$ days is $83.3 \%$, and the likelihood that the duration will not exceed 14 days is $93.2 \%$.

Fifty-seven patients in the cohort underwent unifocalization with an aortopulmonary shunt rather than complete intracardiac repair with an RV-to-pulmonary artery conduit placement. In a subgroup analysis of this group of patients, those with an elevated VD/VT had an OR of 4.8 for prolonged mechanical ventilation $(95 \% \mathrm{CI}, 1.3-16.9$; $P=.014)$ compared with patients with a normal VD/VT (Table 2). However, this association was no longer significant when controlling for weight and CPB time in multivariable logistic regression $(P=.23)$.

A total of 209 patients underwent unifocalization, VSD closure, and RV-to-pulmonary artery conduit placement. Subgroup analysis in this group of patients showed that those with elevated VD/VT had an OR of 1.45 for prolonged mechanical ventilation $(95 \% \mathrm{CI}, 1.3-2.92 ; P=.029)$ compared with patients with normal VD/VT. However, this association was no longer significant when controlling for weight and $\mathrm{CPB}$ time in multivariable logistic regression $(P=.06)$.

\section{DISCUSSION}

We found that patients with TOF/PA/MAPCA are at significant risk of elevated VD/VT in the first 24 hours after 


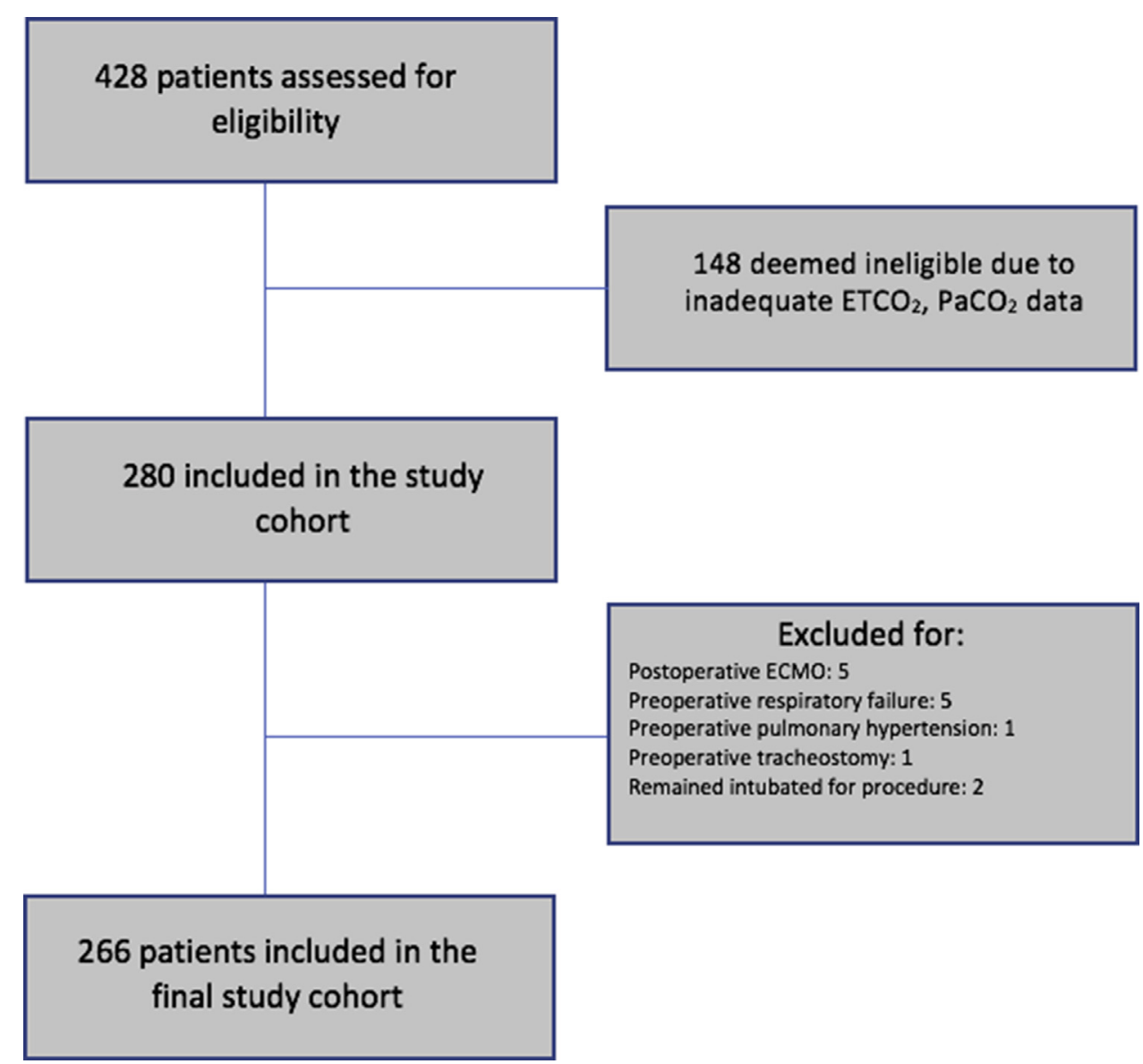

FIGURE 1. CONSORT diagram flowchart for patients included in the study. $\mathrm{ETCO}_{2}$, End-tidal carbon dioxide; $\mathrm{PaCO}_{2}$, arterial partial pressure of carbon dioxide; ECMO, extracorporeal membrane oxygenation.

unifocalization, and that elevated VD/VT is associated with prolonged duration of mechanical ventilation. VD/ VT may allow for risk stratification in the postoperative period and targeted intervention to improve respiratory outcomes, as seen in a previous study targeting optimal positive end-expiratory pressure in patients after cardiac surgery. ${ }^{23}$

We performed a subset analysis in patients who underwent unifocalization but not complete repair and had pulmonary blood flow through an aortopulmonary shunt with

TABLE 1. Baseline characteristics for the overall cohort and in the elevated and normal VD/VT groups

\begin{tabular}{|c|c|c|c|c|}
\hline Characteristic & Overall & $\begin{array}{l}\text { Elevated VD/VT } \\
\quad(n=127)\end{array}$ & Normal VD/VT $(n=138)$ & $P$ value \\
\hline Age, mo, median (IQR) & $7.4(4.7-16)$ & $8.1(3.4-43)$ & $7(5.3-10.8)$ & .65 \\
\hline Female sex, $\mathrm{n} / \mathrm{N}(\%)$ & $142 / 265(54)$ & $64 / 127(50)$ & $78 / 138(56.5)$ & .35 \\
\hline Weight, kg, median (IQR) & $6.7(5.3-10)$ & $6.7(4.9-13.1)$ & $6.7(5.5-8.7)$ & .88 \\
\hline Bypass time, min, mean \pm SD & $230 \pm 118$ & $247 \pm 119$ & $214 \pm 116$ & .03 \\
\hline Previous surgery, n/N (\%) & 109/266 (41) & $54 / 127(43)$ & $55 / 138(40)$ & .79 \\
\hline $\mathrm{RV}$ pressure, $\%$ of $\mathrm{LV}$, mean $\pm \mathrm{SD} *$ & $36 \pm 8$ & $36 \pm 8$ & $36 \pm 8$ & .74 \\
\hline Unifocalized vessels, mean $\pm \mathrm{SD}$ & $3.2 \pm 1.5$ & $3.4 \pm 1.6$ & $3.0 \pm 1.5$ & .053 \\
\hline Delayed sternal closure, n/N (\%) & $68 / 265(26)$ & $41 / 127(32)$ & $27 / 138(20)$ & .018 \\
\hline Postoperative shunt physiology, n/N (\%) & $56 / 265(21)$ & $36 / 127(28)$ & 20/138 (14) & .001 \\
\hline VD/VT, \%, median (IQR) & $19.2(13.8-26.3)$ & $26.8(23.6-32.5)$ & $14(10.6-16.8)$ & $<.001$ \\
\hline
\end{tabular}

$V D / V T$, Dead space ventilation fraction; $I Q R$, interquartile range; $S D$, standard deviation; $R V$, right ventricle; $L V$, left ventricle. *For those who underwent VSD closure. 
TABLE 2. Univariable analysis for associations of clinical factors with prolonged mechanical ventilation

\begin{tabular}{|c|c|c|}
\hline Variable & $\begin{array}{l}\text { OR }(95 \% \text { CI }) \text { for prolonged } \\
\text { mechanical ventilation }\end{array}$ & $\begin{array}{c}P \\
\text { value }\end{array}$ \\
\hline Age & $0.98(0.97-1)$ & .02 \\
\hline Weight & $0.88(0.81-0.96)$ & .003 \\
\hline Female sex & $0.83(0.47-1.47)$ & .50 \\
\hline Bypass time & $1.002(1-1.01)$ & .04 \\
\hline Previous surgery & $1.34(0.74-2.41)$ & .30 \\
\hline RV:LV pressure ratio & $1.32(0.01-111.87)$ & .90 \\
\hline Delayed sternal closure & $5.46(2.95-10.13)$ & .0001 \\
\hline Unifocalized vessels & $1.38(1.15-1.66)$ & .001 \\
\hline Shunted physiology & $2.93(1.56-5.52)$ & .001 \\
\hline $\begin{array}{r}\text { Elevated VD/VT } \\
\text { (dichotomous) }\end{array}$ & $2.22(1.23-3.97)$ & .007 \\
\hline $\begin{array}{l}\text { Elevated VD/VT } \\
\text { (dichotomous) in patients } \\
\text { with shunted physiology }\end{array}$ & $4.8(1.31-16.9)$ & .014 \\
\hline
\end{tabular}

persistent mixing and hypoxemia, hypothesizing that these might have different outcomes. Although an association between VD/VT and prolonged mechanical ventilation was present in univariable analysis, the association was no longer statistically significant after adjustment, possibly related to the small number of patients in this cohort. It should be noted that in the presence of a right-to-left shunt (all patients with unifocalization to an aortopulmonary shunt), the Enghoff modification of the Bohr equation overestimates physiological dead space due to venous admixture. ${ }^{19,24-27}$ Given that the elevated VD/VT in shunted patients might not be due entirely to intrapulmonary dead space ventilation, a different mechanism for prolonged mechanical ventilation must be considered in this subset of our cohort. One possible mechanism is elevated pulmonary blood flow due to a Qp:Qs ratio $>1$, leading to hydrostatic pulmonary edema and difficulty in weaning from the ventilator. Those who underwent complete repair also showed a significant association of increasing VD/ VT with prolonged mechanical ventilation that was no longer significant in the multivariable model. The trend was toward an association and did not reach significance due to diminished power owing to a smaller sample size.

In an effort to provide more a more objective cutoff point for prolonged mechanical ventilation using VD/VT, we constructed an ROC curve and optimized it for the highest possible sensitivity (while maintaining 50\% specificity). The VD/VT cutoff that provided the highest sensitivity was very close to the cutoff of $20 \%$ that was established ad hoc. When using this data in the clinical setting, it is important to identify as many patients at risk for prolonged mechanical ventilation as possible. This led us to determine the cutoff that provided the highest sensitivity. It should be noted that identifying a patient who is at risk but does not ultimately require prolonged mechanical ventilation would not expose this patient to any further morbidity.

The mechanism of elevated VD/VT in these patients cannot be inferred from the findings of this retrospective

\section{Dead Space Ventilation and the Duration of Mechanical Ventilation}

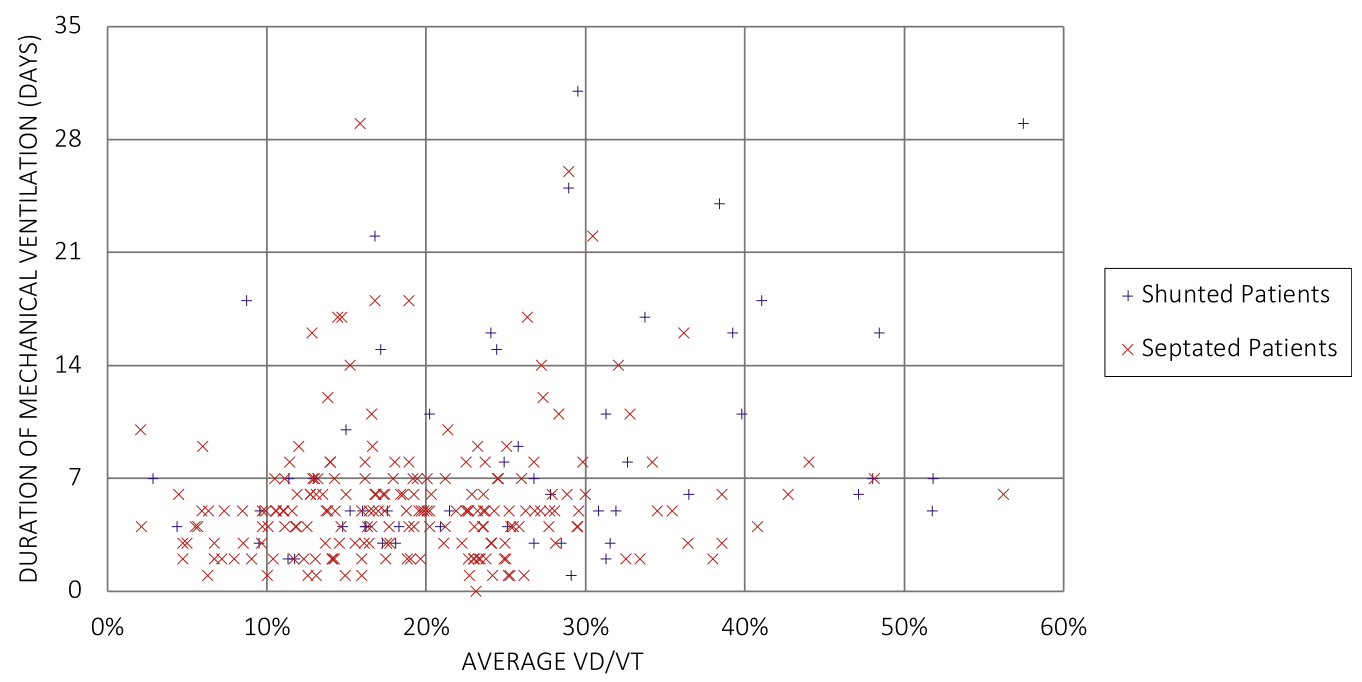

FIGURE 2. Duration of mechanical ventilation versus 24-hour average dead space ventilation fraction (VD/VT). Shunted patients are denoted by a blue cross, and septated patient are denoted by a red X. Dark lines represent the a priori determined cutoffs for prolonged mechanical ventilation ( 7 days) and elevated VD/VT $(20 \%)$. 


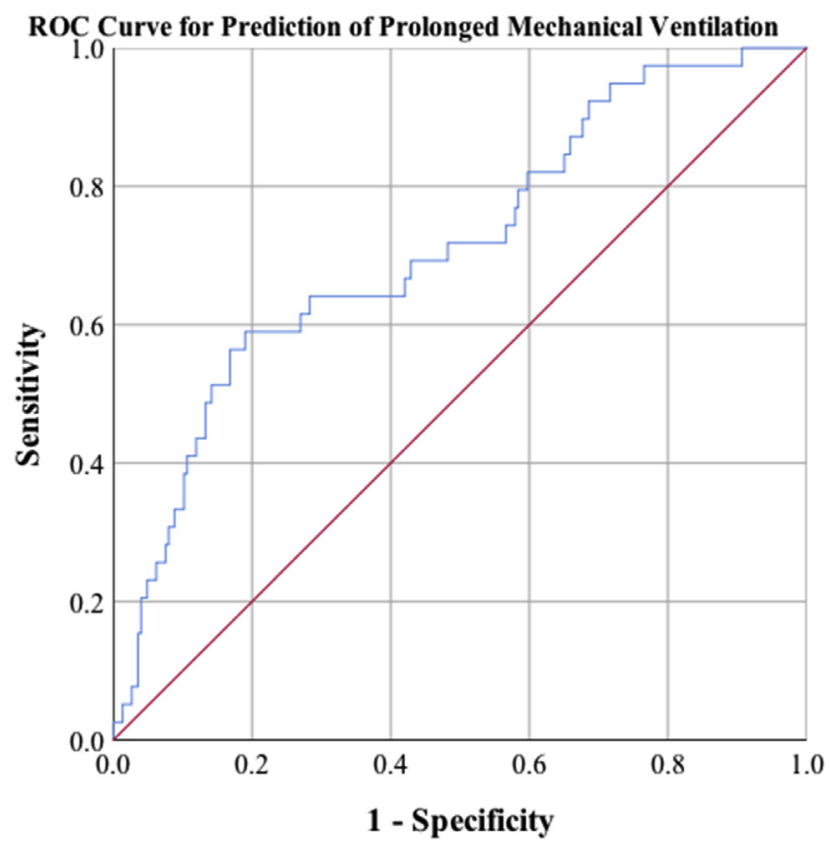

FIGURE 3. Receiver operating characteristic (ROC) curve for dead space ventilation fraction (VD/VT) for the diagnosis of prolonged mechanical ventilation. The area under the ROC curve for VD/VT is $0.72(P<.001)$.

study. However, one plausible explanation is that patients with longer CPB duration, and thus more extensive pulmonary artery reconstruction, were more likely to develop impaired gas exchange and elevated VD/VT because of extensive lung dissection.

Regardless of the etiology of elevated VD/VT, the clinical implications are apparent. With elevated VD/VT and $\mathrm{PaCO}_{2}$, patients may develop compensatory tachypnea, which may contribute to the need for prolonged respiratory support and increased metabolic demands. Our findings are consistent with those of Ong and colleagues ${ }^{21}$ and Shakti and colleagues. ${ }^{20}$ Ong and colleagues ${ }^{21}$ measured VD/VT in patients with various types of congenital heart disease in the postoperative period and found higher VD/VT and prolonged mechanical ventilation in those with residual shunt physiology. Shakti and colleagues ${ }^{20}$ studied VD/VT after stage I palliation for single-ventricle heart disease and found poorer clinical outcomes in those with elevated $\mathrm{VD} / \mathrm{VT}$, such as prolonged respiratory failure, reintubation, and longer hospital stay.

Our finding that elevated VD/VT $(>20 \%)$ had a negative predictive value of $83 \%$ for a duration of mechanical ventilation $<7$ days and $93 \%$ for $<14$ days may be helpful in immediate postoperative planning and family counseling.

Further prospective investigation is needed to confirm the association between dead space ventilation and outcomes, and also to allow for more robust control of potential biases and confounders. Interventional trials are also indicated to determine whether specific ventilation strategies and/or

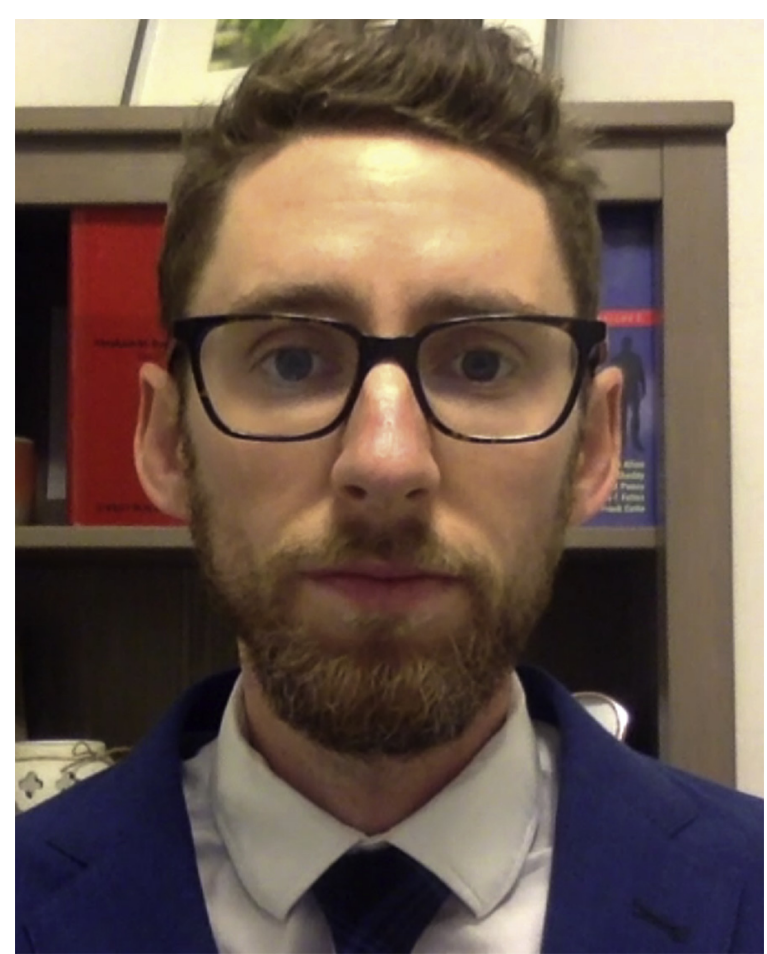

VIDEO 1. Author A. Koth explains the complex care of patients with tetralogy of Fallot with pulmonary atresia and major aortopulmonary collateral arteries after unifocalization, and describes how the findings of this study may aid in their postoperative care. Video available at: https:// www.jtcvs.org/article/S0022-5223(18)31227-3/fulltext.

medical interventions such as inhaled nitric oxide, which has been shown to decrease VD/VT, ${ }^{28}$ or enhanced pulmonary toilet with bronchodilator or mucolytic therapy could decrease VD/VT and subsequently reduce the duration of mechanical ventilation.

\section{Limitations}

This study is limited by its retrospective design. In retrospective cohort study, there are also issues with missing data. Data in this study were complete with the exception of RV:left ventricle pressure ratio. This variable was used in the univariable analysis but did not meet the criteria for inclusion in the multivariable model and thus was not included. In addition, these findings reflect the experience of a single center that treats a large number of patients with TOF/PA/MAPCAs and as such might not be generalizable to centers with different management approaches. We also recognize the likelihood of overestimating VD/VT in patients with residual shunt physiology as described above. This overestimation may have influenced our results.

\section{CONCLUSIONS}

We studied a large, homogeneous cohort and found that elevated VD/VT occurred in approximately one-half of all patients with TOF/PA/MAPCA undergoing unifocalization, 
and that those with elevated VD/VT experienced poor postoperative outcomes, including prolonged mechanical ventilation and longer ICU length of stay. The association of VD/ VT with prolonged postoperative recovery provides a target for the management of these patients in the cardiovascular ICU that may be modified to improve outcomes (Video 1).

\section{Conflict of Interest Statement}

Authors have nothing to disclose with regard to commercial support.

\section{References}

1. Asija R, Hanley FL, Roth SJ. Postoperative respiratory failure in children with tetralogy of Fallot, pulmonary atresia, and major aortopulmonary collaterals: a pilot study. Pediatr Crit Care Med. 2013;14:384-9.

2. Carson SS. Outcomes of prolonged mechanical ventilation. Curr Opin Crit Care. 2006; 12:405-11.

3. Cox CE, Carson SS, Lindquist JH, Olsen MK, Govert JA, Chelluri L. Differences in one-year health outcomes and resource utilization by definition of prolonged mechanical ventilation: a prospective cohort study. Crit Care. 2007;11:R9.

4. Dewar DM, Kurek CJ, Lambrinos J, Cohen IL, Zhong Y. Patterns in costs and outcomes for patients with prolonged mechanical ventilation undergoing tracheostomy: an analysis of discharges under diagnosis-related group 483 in New York State from 1992 to 1996. Crit Care Med. 1999;27:2640-7.

5. Hill AD, Fowler RA, Burns KE, Rose L, Pinto RL, Scales DC. Long-term outcomes and health care utilization following prolonged mechanical ventilation. Ann Am Thorac Soc. 2017; 14:355-62.

6. Lai CC, Shieh JM, Chiang SR, Chiang KH, Weng SF, Ho CH, et al. The outcomes and prognostic factors of patients requiring prolonged mechanical ventilation. Sci Rep. 2016;6:28034.

7. Lone NI, Walsh TS. Prolonged mechanical ventilation in critically ill patients: epidemiology, outcomes and modelling the potential cost consequences of establishing a regional weaning unit. Crit Care. 2011;15:R102.

8. López-Herce Cid J, Leyton Avilés P, Urbano Villaescusa J, Cidoncha Escobar E, Del Castillo Peral J, Carrillo Alvarez A, et al. Risk factors for prolonged mechanical ventilation after cardiac surgery in children. Med Intensiva. 2008;32:369-77 [in Spanish].

9. Pilmer SL. Prolonged mechanical ventilation in children. Pediatr Clin North Am. 1994;41:473-512.

10. Prodhan P, Kalikivenkata G, Tang X, Thomas K, Byrnes J, Imamura M, et al. Risk factors for prolonged mechanical ventilation for children on ventricular assist device support. Ann Thorac Surg. 2015;99:1713-8.

11. Traiber C, Piva JP, Fritsher CC, Garcia PC, Lago PM, Trotta EA, et al. Profile and consequences of children requiring prolonged mechanical ventilation in three Brazilian pediatric intensive care units. Pediatr Crit Care Med. 2009;10:375-80.

12. Gil-Ruiz Gil-Esparza MA, Alcaraz Romero AJ, Romero Otero A, Gil Villanueva N, Sanavia Morán E, Rodríguez Sánchez de la Blanca A, et al. Prognostic relevance of early AKI according to pRIFLE criteria in children undergoing cardiac surgery. Pediatr Nephrol. 2014;29:1265-72.
13. Crow SS, Robinson JA, Burkhart HM, Dearani JA, Golden AW. Duration and magnitude of vasopressor support predicts poor outcome after infant cardiac operations. Ann Thorac Surg. 2014;98:655-61.

14. Kipps AK, Wypij D, Thiagarajan RR, Bacha EA, Newburger JW. Blood transfusion is associated with prolonged duration of mechanical ventilation in infants undergoing reparative cardiac surgery. Pediatr Crit Care Med. 2011;12:52-6.

15. Székely A, Sápi E, Király L, Szatmári A, Dinya E. Intraoperative and postoperative risk factors for prolonged mechanical ventilation after pediatric cardiac surgery. Paediatr Anaesth. 2006;16:1166-75.

16. Kerr AA. Dead space ventilation in normal children and children with obstructive airways diease. Thorax. 1976;31:63-9.

17. Cook CD, Cherry RB, O'Brien D, Karlberg P, Smith CA. Studies of respiratory physiology in the newborn infant. I. Observations on normal premature and full term infants. J Clin Invest. 1955;34(7 Part 1):975-82.

18. Nelson NM, Prod'hom LS, Cherry RB, Lipsitz PJ, Smith CA. Pulmonary func tion in the newborn infant, V: trapped gas in the normal infant's lung. J Clin Invest. 1963;42:1850-7.

19. Burrows FA. Physiologic dead space, venous admixture, and the arterial to endtidal carbon dioxide difference in infants and children undergoing cardiac surgery. Anesthesiology. 1989;70:219-25.

20. Shakti D, McElhinney DB, Gauvreau K, Yarlagadda VV, Laussen PC, Betit P, et al. Pulmonary deadspace and postoperative outcomes in neonates undergoing stage 1 palliation operation for single ventricle heart disease. Pediatr Crit Care Med. 2014;15:728-34.

21. Ong T, Stuart-Killion RB, Daniel BM, Presnell LB, Zhuo H, Matthay MA, et al Higher pulmonary dead space may predict prolonged mechanical ventilation after cardiac surgery. Pediatr Pulmonol. 2009;44:457-63.

22. Malhotra SP, Hanley FL. Surgical management of pulmonary atresia with ven tricular septal defect and major aortopulmonary collaterals: a protocol-based approach. Semin Thorac Cardiovasc Surg Pediatr Card Surg Annu. 2009;12: $145-51$.

23. Blankman P, Shono A, Hermans BJ, Wesselius T, Hasan D, Gommers D. Detec tion of optimal PEEP for equal distribution of tidal volume by volumetric capnography and electrical impedance tomography during decreasing levels of PEEP in post-cardiac surgery patients. Br J Anaesth. 2016;116:862-9.

24. Fletcher R, Jonson B, Cumming G, Brew J. The concept of deadspace with special reference to the single breath test for carbon dioxide. Br J Anaesth. 1981;53: 77-88.

25. Wagner PD. Causes of a high physiological dead space in critically ill patients Crit Care. 2008; 12:148.

26. Suarez-Sipmann F, Santos A, Böhm SH, Borges JB, Hedenstierna G, Tusman G. Corrections of Enghoff's dead space formula for shunt effects still overestimate Bohr's dead space. Respir Physiol Neurobiol. 2013;189:99-105.

27. Lumb AB. Nunn's Applied Respiratory Physiology. 8th ed. Edinburgh, UK Elsevier; 2016.

28. Skimming JW, Banner MJ, Spalding HK, Jaeger MJ, Burchfield DJ, Davenport PW. Nitric oxide inhalation increases alveolar gas exchange by decreasing deadspace volume. Crit Care Med. 2001;29:1195-200.

Key Words: congenital heart disease, dead space ventilation fraction, prolonged mechanical ventilation, pulmonary atresia, tetralogy of Fallot 